\title{
How much time is necessary to confirm the diagnosis of permanent complete cervical spinal cord injury?
}

\author{
Osamu Kawano ${ }^{1} \cdot$ Takeshi Maeda $^{1} \cdot$ Eiji Mori ${ }^{1} \cdot$ Tsuneaki Takao $^{1} \cdot$ Hiroaki Sakai ${ }^{1}$ Muneaki Masuda $\mathbb{D}^{1} \cdot$ \\ Yuichiro Morishita $^{1} \cdot$ Tetsuo Hayashi $^{1} \cdot$ Kensuke Kubota $^{1} \cdot$ Kazu Kobayakawa $^{1} \cdot$ Hironari Kaneyama $^{1}$
}

Received: 14 May 2019 / Revised: 4 September 2019 / Accepted: 6 September 2019 / Published online: 16 October 2019

(c) The Author(s), under exclusive licence to International Spinal Cord Society 2019

\begin{abstract}
Study design Retrospective chart audits.

Objective To investigate the optimal timing at which permanent complete cervical spinal cord injury (CSCI) can be confirmed when evaluating paralysis caused by traumatic CSCI.

Setting Department of Orthopedic Surgery, Spinal Injuries Center, Japan.

Methods Two-hundred and three patients with CSCI that was classified with an American Spinal Injury Association (ASIA) Impairment Scale (AIS) grade A (AIS A) within $72 \mathrm{~h}$ of the initial diagnosis of traumatic CSCI were included in the present study. Neurological data from the time of the initial diagnosis to 1 year after the injury were extracted. The number of those with recovery from AIS A and changes of AIS in the recovery were examined.

Results Thirty-five of $203(17 \%)$ patients whose injuries were initially classified with an AIS A showed recovery from AIS A. Thirty-four of 35 (97\%) patients showed recovery from AIS A within 8 weeks after injury.

Conclusion If CSCI patients with AIS A have not recovered by 8 weeks, the likelihood that they will recover from AIS A is marginal. However, this conversely means that we must consider the possibility that a patient with a traumatic CSCI classified with an AIS A may still show recovery from AIS A within the first 8 weeks after injury.
\end{abstract}

\section{Introduction}

It is well-known that spontaneous improvement of cervical spinal cord injury (CSCI) can be seen as a natural history in people with incomplete traumatic CSCI [1]. It is also a wellknown fact that the degree of this improvement can be quite remarkable in the acute phase. Even if CSCI patients present as American Spinal Injury Association (ASIA) Impairment Scale (AIS) grade A (AIS A) just after injury, they may show some neurologic recovery.

Multiple interventions or clinical trials (e.g., surgery, drug administration, regenerative medicine, etc.) have been attempted in order to help improve the neurological outcomes of patients with traumatic CSCI [2-9]. Several new intervention approaches recently have been attempted at

Osamu Kawano

orthosic@orange.ocn.ne.jp

1 Department of Orthopaedic Surgery, Spinal Injuries Center, Fukuoka, Japan earlier stages, in light of the notion that greater improvement of the prognosis may be achieved if an intervention is attempted as early as possible. However, it is highly likely that the assessment of the outcome following an intervention will be inaccurate if the intervention is performed in the acute phase, when there is a high proportion of people with AIS A who have recovery potential $[10,11]$.

Many reports concerning the prognosis of incomplete CSCI have been published. Ultimately incomplete CSCI includes both incomplete CSCI just after the injury and recovery from initially complete CSCI in the acute phase. Complete CSCI is defined as a complete and permanent loss of the ability to send sensory and motor nerve impulses thorough the affected spinal level [12]. There have been some reports concerning the prognosis of complete SCI resulting from interventions or clinical trials. However, there have been few reports on the natural history or the long-term follow-up of complete CSCI [12-14]. In particular, there are no reports indicating a clear time frame of the recovery point from AIS A to incomplete SCI $[12,15]$. There are no reports available concerning the length of time after injury required to diagnose a person as having a 
permanent complete CSCI once the possibility of recovery from AIS A has been ruled out. In this study, we aimed to investigate the optimal timing at which complete CSCI can be confirmed when evaluating paralysis caused by traumatic CSCI.

\section{Methods}

The study included 203 patients classified with an American Spinal Injury Association (ASIA) Impairment Scale (AIS) grade A (AIS A) [16] within $72 \mathrm{~h}$ of sustsaining traumatic CSCI from 2006 to 2017. All patients underwent treatment at our hospital alone from the acute phase (within $72 \mathrm{~h}$ after injury) to the chronic phase. Records were taken from an investigation of our institute's database. We extracted the neurological data of each patient at the time of the initial diagnosis, within $72 \mathrm{~h}$ after injury, at $1,4,6$, and 8 weeks after injury, at 3, 4, 5, 6, and 8 months after injury, and at 1 year after injury.

The participants included 128 patients with CSCI with bone injury (dislocation and/or fracture) and 75 patients with CSCI without bone injury. We performed prompt surgery for patients with bone injury within $48 \mathrm{~h}$. In contrast, we attempted conservative treatment for patients without bone injury in the acute phase. In all cases, rehabilitation began the day after admission.

Among 203 patients with CSCI classified with an AIS A within $72 \mathrm{~h}$ after injury, we examined the number and changes of those with recovery from AIS A.

Statistical analyses were performed using the Chi-square test for comparing those with CSCI with or without bone injury, looking at the rate of AIS A with recovery potential and the prognosis of those with AIS A with recovery potential. Significance was set at a value of $P<0.05$. Statistical analyses were performed using JAMP 13 (SAS Institute Inc., Cary, NC, USA) computer software.

\section{Results}

Thirty-five of the 203 (17\%) patients whose injuries were initially classified as AIS A showed recovery. Fifteen of the $128(12 \%)$ patients with bone injury showed recovery from AIS A and 20 of the 75 (27\%) patients without bone injury showed recovery. Despite early interventional surgery, the rate of those with AIS A with recovery potential in CSCI with bone injury was significantly worse than that of CSCI without bone injury (Fig. 1).

Seven of 35 (20\%) patients had improved to AIS B or C at $72 \mathrm{~h}$ after injury. Moreover, ten of 35 (29\%) patients showed recovery from AIS A within 1 week after injury, while 17 showed recovery from AIS A at 4, 6, and 8 weeks

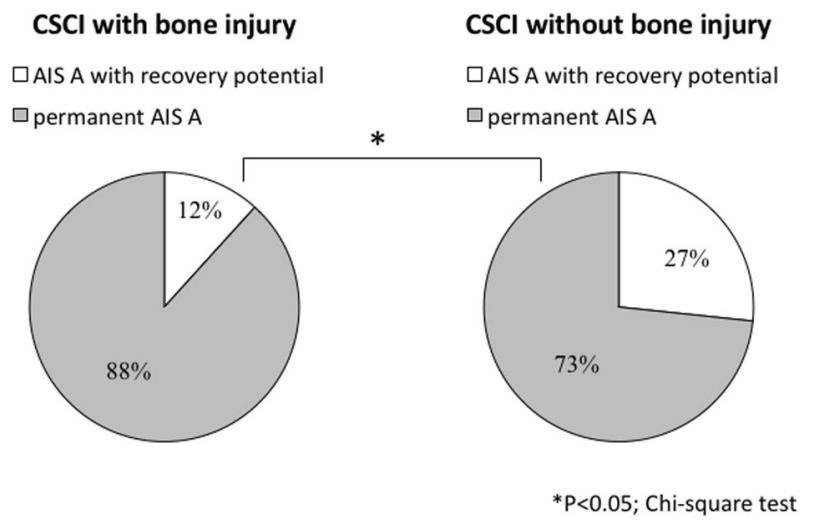

Fig. 1 Rate of AIS A with recovery potential. Fifteen of the 128 (12\%) patients with bone injury showed recovery from AIS A and 20 of the $75(27 \%)$ patients without bone injury showed recovery from AIS A. The rate of AIS A with recovery potential in CSCI with bone injury was significantly worse than that of CSCI without bone injury. $* P<$ 0.05 , Chi-square test

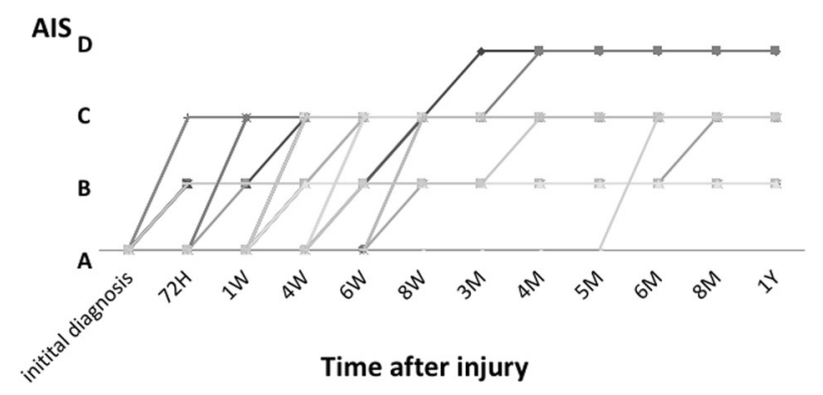

Fig. 2 Changes of AIS in initially AIS A with recovery potential. $(n=$ 35). Thirty-four of 35 patients (97\%) showed recovery from AIS A within 8 weeks after injury. The remaining patient was improved to AIS C (ASIA motor score in this case changed from 0 to 3 ) at 6 months after injury. The probability of recovery from AIS A was found to be marginal $>8$ weeks after injury

(27 of 35 patients, $77 \%$ [including all patients who showed recovery from AIS A at the preceding time points]), 4 (31 of 35 patients, $89 \%$ ), and 3 ( 34 of 35 patients, $97 \%$ ), respectively. By 8 weeks after injury, $97 \%$ of AIS A patients with recovery potential showed neurological improvement. The remaining patient improved to AIS $\mathrm{C}$ at 6 months after injury (Fig. 2 and Tables 1 and 2). The ASIA mot.or score in this case changed from 0 to 3 at 6 months after the injury. The probability of recovery from AIS A was found to be marginal $>8$ weeks after injury.

The prognosis of patients classified as AIS A at the initial assessment is shown in Table 3 . Among the 35 patients with recovery from AIS A, two who improved to AIS B within $72 \mathrm{~h}$ after injury ultimately recovered to AIS D. The remaining 33 cases improved to AIS B or C. Seven of the $15(47 \%)$ patients with bone injury showed motor recovery (up to AIS C, D) and 18 of the 20 (90\%) without bone injury showed motor recovery (up to AIS C). The rate of 


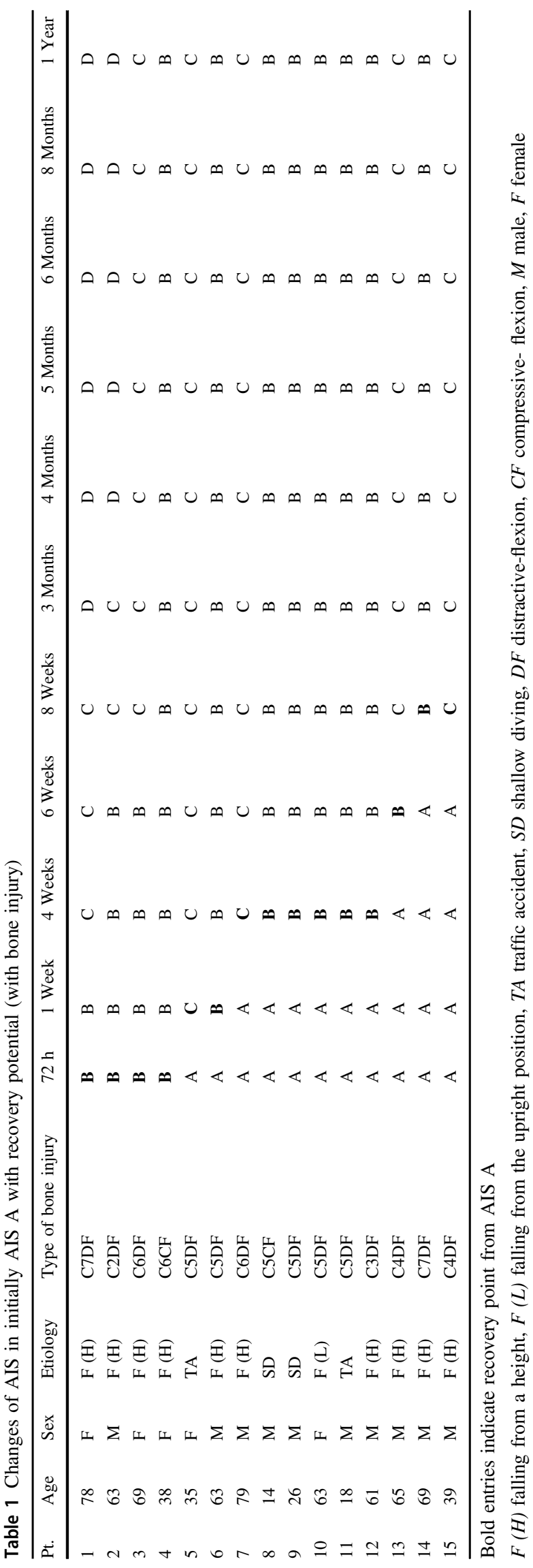

motor recovery in CSCI with bone injury was significantly worse than that of CSCI without bone injury (Fig. 3).

\section{Discussion}

It is well-known that spontaneous improvement of neurological status is observed in CSCI. With time, neurological status improves in a large percentage of patients with incomplete CSCI [1]. However, in patients with incomplete CSCI, they sometimes are classified initially as AIS A just after injury.

There have been few reports on the natural history recovery in those with complete CSCI [12-14]. Reports on the rate of recovery from AIS A and reports on the prognostic factors associated with CSCI recovery are available; however, the time that is required to confirm the diagnosis of permanent complete CSCI in patients with traumatic CSCI is not well documented.

Mori et al. [13] reported on neurological improvement after conservative treatment in patients with complete motor paralysis caused by acute CSCI without bone and disc injury. According to their report, $30 \%$ of the patients who were considered to have an AIS A within $72 \mathrm{~h}$ after a traumatic CSCI showed neurological improvement to motor incomplete CSCI. El Tecle et al. [12] conducted a metaanalysis of data reporting on AIS A patients and reported that the overall rate of conversion of AIS A was 33.3\%. However, the study did not ascertain the time at which the initial evaluation was conducted or the time at which improvement or conversion occurred.

Again, AIS A in the acute phase after injury is not equal to permanent complete CSCI. Although the majority of people classified as AIS A in the acute phase may ultimately show complete CSCI, some will spontaneously improve to AIS B, C, D. If patients who were initially classified as AIS $\mathrm{A}$ in the acute phase receive therapeutic intervention, and then subsequently show recovery from AIS A, whether or not their improvement is influenced by the therapeutic intervention or merely represents a spontaneous improvement remains unclear. When, then, should we determine that the CSCI is permanent in patients initially classified as AIS A in the acute phase?

The present study demonstrates that CSCI can almost certainly be classified as permanent complete CSCI if recovery from AIS A has not been observed within 8 weeks after the injury. With these results in mind, we should carefully evaluate the effects of therapeutic interventions (e.g., surgery, the administration of drugs, regenerative medicine, etc.) performed with the aim of achieving neurological improvement of AIS A CSCI in the 8-week period after the injury. Additionally, we should evaluate more carefully the effect of interventions for CSCI because AIS A 


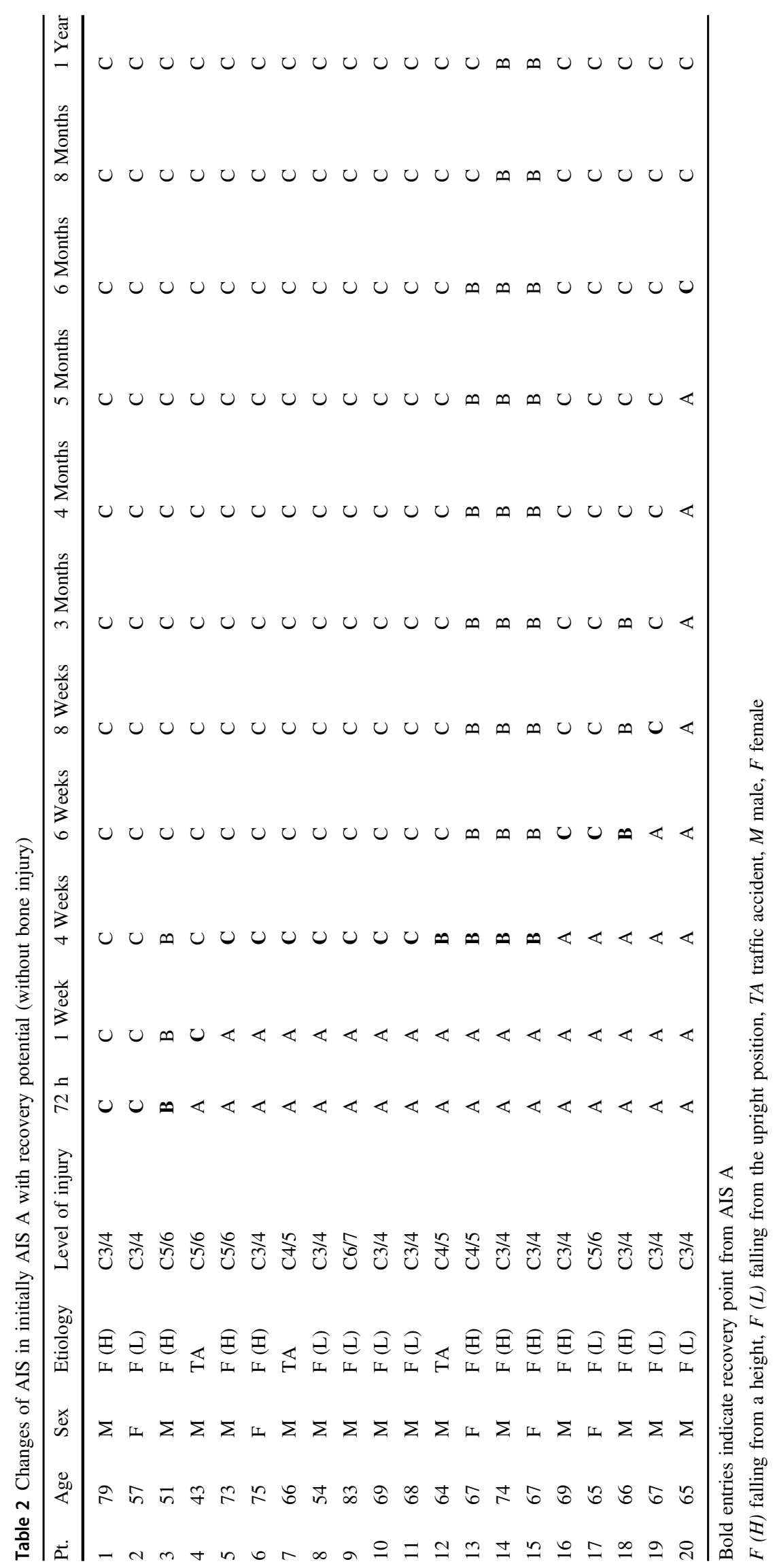


Table 3 Prognosis of AIS A at initial assessment

\begin{tabular}{llllllll}
\hline & Initial AIS A & AIS after 1 year & AIS A with \\
\cline { 2 - 6 } & & A & B & C & D & $\begin{array}{l}\text { recovery } \\
\text { potential }\end{array}$ \\
\hline $\begin{array}{l}\text { CSCI with } \\
\text { bone injury }\end{array}$ & 128 & 113 & 8 & 5 & 2 & 15 \\
$\begin{array}{l}\text { CSCI without } \\
\text { bone injury }\end{array}$ & 75 & 55 & 2 & 18 & 0 & 20 \\
\hline
\end{tabular}

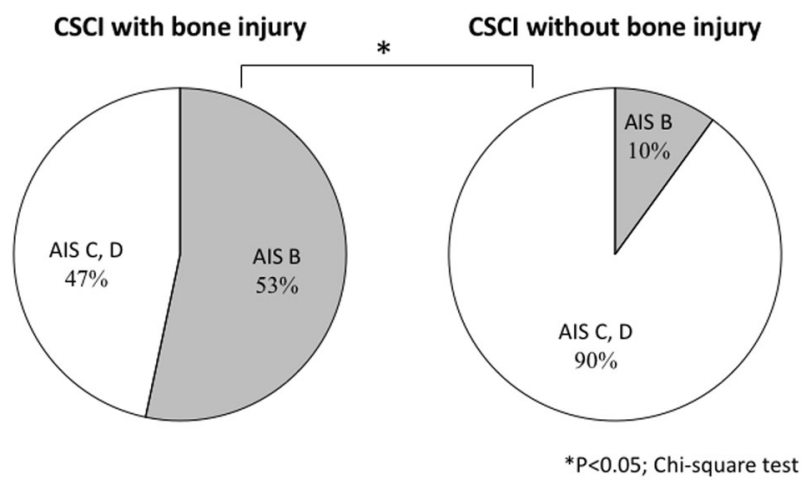

Fig. 3 Rate of motor recovery in initial AIS A with recovery potential. Seven of the $15(47 \%)$ patients with bone injury showed motor recovery (up to AIS C, D) and 18 of the $20(90 \%)$ patients without bone injury showed motor recovery (up to AIS C).The rate of motor recovery in CSCI with bone injury was significantly worse than that of CSCI without bone injury. $* P<0.05$, Chi-square test

cases are common in the very acute phase (i.e., within $72 \mathrm{~h}$ after injury).

Despite early interventional surgery, the rate of AIS A with recovery potential in CSCI with bone injury was significantly worse than that of CSCI without bone injury in the present study. Additionally, the reported improvement rate of those classified as AIS A differs among various studies (Table 4) [4, 8, 9, 13]. The reason for such differences possibly is due not to the intervention itself, but to differences in the rate of inclusion of those with AIS A with recovery potential in the acute phase of CSCI. The prognosis of those with AIS A with recovery potential was also different between CSCI with bone injury and CSCI without bone injury, showing that, the rate of motor recovery in CSCI with bone injury was significantly worse than that of CSCI without bone injury. The reason for such differences might be due not to the intervention surgery, but to differences in the degree of damage to the spinal cord. The relationship between the degree of paralysis and traumatic force has been reported in the past [17].

Although this study assessed a relatively small sample $(n=203)$ and despite the fact that the surgical intervention was performed within $48 \mathrm{~h}$ for patients with bone injury, the results of the present study sufficiently demonstrate the
Table 4 Differences among the reported recovery rate from AIS A

\begin{tabular}{|c|c|c|c|}
\hline Author and year & $\begin{array}{l}\text { Evaluation } \\
\text { w/in } 72 \mathrm{~h}\end{array}$ & Type of intervention & $\begin{array}{l}\text { Rate of recovery } \\
\text { from AIS A (\%) }\end{array}$ \\
\hline $\begin{array}{l}\text { Vaccaro et al. } \\
\text { [9], } 1997\end{array}$ & Yes & $\begin{array}{l}\text { Early op (mean } \\
1.8 \text { days) } \\
\text { Late op (mean } \\
16.8 \text { days) }\end{array}$ & $\begin{array}{l}22 \\
13\end{array}$ \\
\hline $\begin{array}{l}\text { Papadopoulos } \\
\text { et al. [8], } 2002\end{array}$ & Yes & $\begin{array}{l}\text { Early op (w/in } 24 \text { h) } \\
\text { Late op }\end{array}$ & $\begin{array}{l}55 \\
19\end{array}$ \\
\hline $\begin{array}{l}\text { Fehlings et al. } \\
\text { [4], } 2012\end{array}$ & Yes & $\begin{array}{l}\text { Early op (mean } 14.2 \mathrm{~h} \text { ) } \\
\text { Late op (mean } 48.3 \mathrm{~h})\end{array}$ & $\begin{array}{l}43 \\
33\end{array}$ \\
\hline $\begin{array}{l}\text { Mori et al. } \\
\text { [13], } 2018\end{array}$ & Yes & None & 30 \\
\hline $\begin{array}{l}\text { Present } \\
\text { study, } 2019\end{array}$ & Yes & $\begin{array}{l}\text { Early op (w/in } 48 \mathrm{~h} \text {, } \\
\text { with bone injury) } \\
\text { None (w/out bone } \\
\text { injury) }\end{array}$ & $\begin{array}{l}11.7 \\
26.7\end{array}$ \\
\hline
\end{tabular}

optimal time frame for confirming the diagnosis of permanent complete CSCI.

\section{Conclusion}

If CSCI patients classified as AIS A have not recovered by 8 weeks, the likelihood that they will recover from AIS A is marginal. However, this conversely means that we must consider the possibility that a patient with a traumatic CSCI classified as AIS A may still show recovery from AIS A within the first 8 weeks after injury.

\section{Data archiving}

Data sets generated and/or analyzed during the current study are not publicly available due to the inclusion of private information of patients but are available from the corresponding author on reasonable request.

Funding The manuscript submitted does not contain information about medical device(s)/drug(s). No funds were received in support of this work. No benefits in any form have been or will be received from a commercial party related directly or indirectly to the subject of this manuscript.

Author contributions OK designed the studies, performed the statistical analysis, and drafted the manuscript. TK and EM supervised the oveall project. TT, HS, MM, YM, TH, KK, KK and HK performed the data collection. All authors read and approved the final manuscript.

\section{Compliance with ethical standards}

Conflict of interest The authors declare that they have no conflict of interest.

Statement of Ethics This study was approved by the Ethics Review Board of the Spinal Injuries Center. This article does not contain any studies with human participants or animals performed by any of the authors. 
Informed consent Informed consent was obtained from all of the patients who were included in the present study.

Publisher's note Springer Nature remains neutral with regard to jurisdictional claims in published maps and institutional affiliations.

\section{References}

1. Curt A, Van Hedel HJ, Klaus D, Dietz V, EM-SCI Study Group. Recovery from a spinal cord injury: significance of compensation, neural plasticity, and repair. J Neurotrauma. 2008;25:677-85.

2. Bracken MB, Shepard MJ, Holford TR, Leo-Summers L, Aldrich EF, Fazl M, et al. Administration of methylprednisolone for 24 or $48 \mathrm{~h}$ or tirilazad mesylate for $48 \mathrm{~h}$ in the treatment of acute spinal cord injury. Results of the Third National Acute Spinal Cord Injury Randomized Controlled Trial. National Acute Spinal Cord Injury Study. JAMA. 1997;277:1597-604.

3. Bracken MB, Shepard MJ, Holford TR, Leo-Summers L, Aldrich EF, Fazl M, et al. Methylprednisolone or tirilazad mesylate administration after acute spinal cord injury: 1-year follow up. Results of the third National Acute Spinal Cord Injury randomized controlled trial. J Neurosurg. 1998;89:699-706.

4. Fehlings MG, Vaccaro A, Wilson JR, Singh A, W Cadotte D, Harrop JS, et al. Early versus delayed decompression for traumatic cervical spinal cord injury: results of the Surgical Timing in Acute Spinal Cord Injury Study (STASCIS). PLoS ONE. 2012;7: e32037.

5. Geisler FH, Dorsey FC, Coleman WP. Recovery of motor function after spinal-cord-injury -a randomized, placebo-controlled trial with GM-1 ganglioside. N Engl J Med. 1991;324:1829-38.

6. Granger N, Blamires H, Franklin RJ, Jeffery ND. Autologous olfactory mucosal cell transplants in clinical spinal cord injury: a randomized double-blinded trial in a canine translational model. Brain. 2012;135:3227-37.

7. Lima C, Pratas-Vital J, Escada P, Hasse-Ferreira A, Capucho C, Peduzzi JD. Olfactory mucosa autografts in human spinal cord injury: a pilot clinical study. J Spinal Cord Med. 2006;29: 191-206.
8. Papadopoulos SM, Selden NR, Quint DJ, Patel N, Gillespie B, Grube $S$. Immediate spinal cord decompression for cervical spinal cord injury: feasibility and outcome. J Trauma. 2002;52:323-32.

9. Vaccaro AR, Daugherty RJ, Sheehan TP, Dante SJ, Cotler JM, Balderston RA, et al. Neurologic outcome of early versus late surgery for cervical spinal cord injury. Spine (Philos Pa 1976). 1997;22:2609-13.

10. Kramer JL, Lammertse DP, Schubert M, Curt A, Steeves JD. Relationship between motor recovery and independence after sensorimotor-complete cervical spinal cord injury. Neurorehabil Neural Repair. 2012;26:1064-71.

11. Zariffa J, Kramer JL, Fawcett JW, Lammertse DP, Blight AR, Guest J, et al. Characterization of neurological recovery following traumatic sensorimotor complete thoracic spinal cord injury. Spinal Cord. 2011;49:463-71.

12. El Tecle NE, Dahdaleh NS, Bydon M, Ray WZ, Torner JC, Hitchon PW. The natural history of complete spinal cord injury: a pooled analysis of 1162 patients and a meta-analysis of modern data. J Neurosurg Spine. 2018;28:436-43.

13. Mori E, Ueta T, Maeda T, Ideta R, Yugue I, Kawano O, et al. Sequential neurological improvement after conservative treatment in patients with complete motor paralysis caused by cervical spinal cord injury without bone and disc injury. J Neurosurg Spine. 2018;29:1-9.

14. Steeves JD, Kramer JK, Fawcett JW, Cragg J, Lammertse DP, Blight AR, et al. Extent of spontaneous motor recovery after traumatic cervical sensorimotor complete spinal cord injury. Spinal cord. 2011;49:257-65.

15. van Middendrop JJ, Hosman AJ, Pouw MH, EM-SCI Study Group, Van de Meent H. ASIA impairment scale conversion in traumatic SCI: is it related with the ability to walk? A descriptive comparison with functional ambulation outcome measures in 273 patients. Spinal Cord. 2009;47:555-60.

16. Kirshblum SC, Burns SP, Biering-Sorensen F, Donovan W, Graves DE, Jha A, et al. International standards for neurological classification of spinal cord injury (revised 2011). J Spinal Cord Med. 2011;34:535-46.

17. Kawano O, Maeda T, Mori E, Yugue I, Takao T, Sakai H, et al. Influence of spinal cord compression and traumatic force on the severity of cervical spinal cord injury associated with ossification of the posterior longitudinal ligament. Spine. 2014;39:1108-12. 